\title{
ABORDAGEM SOBRE A PRÁTICA EDUCATIVA INTERDISCIPLINAR NO COTIDIANO ESCOLAR
}

\section{ARTIGO ORIGINAL}

LIMA, Suelma Da Silva Aguiar ${ }^{1}$

LIMA, Suelma Da Silva Aguiar. Abordagem sobre a prática educativa interdisciplinar no cotidiano escolar. Revista Científica Multidisciplinar Núcleo do Conhecimento. Ano 05, Ed. 02, Vol. 01, pp. 161-172. Fevereiro de 2020. ISSN: 24480959, Link de acesso: https://www.nucleodoconhecimento.com.br/educacao/praticaeducativa-interdisciplinar

\section{RESUMO}

O artigo desenvolvido busca fazer uma análise da interdisciplinaridade aplicada à sala de aula e mostrar a importância da prática interdisciplinar no processo educativo, suas contribuições para o desenvolvimento do ser humano tanto no aspecto intelectual quanto no social, de tal maneira que este na sua interação com o meio mantenha uma convivência harmoniosa em meio a uma sociedade que se mostra bastante fragmentada na sua forma de organização e aos valores que tem transmitido às futuras gerações. Pretende-se analisar o conceito de interdisciplinaridade e sua relação com a prática no cotidiano escolar, além da forma como esta vem sendo interpretada pelo educador quando este envolve a produção e a execução do planejamento escolar no processo de ensino e aprendizagem. Aponta-se para a fundamentação e reflexão do planejamento enquanto instrumento abalizador da ação pedagógica. Considera-se importante $\mathrm{o}$ conhecimento e prática da interdisciplinaridade no contexto escolar tendo em vista que torna esse processo

\footnotetext{
${ }^{1}$ Graduada em Pedagogia pela Universidade Estadual do Maranhão. Pós-graduada em Gestão, Supervisão e Orientação Educacional pela Faculdade Santa Fé São LuísMA.
} 
integrador de conhecimentos possibilitando a reflexão e a ação da formação de indivíduos críticos.

Palavras-Chaves: Interdisciplinaridade, prática, interação, planejamento.

\section{INTRODUÇÃO}

Quando se trata de aprendizagem, vários meios são utilizados para desenvolvê-la com o intuito de formar seres humanos capazes de interagir com a sociedade que está constantemente sofrendo modificações, nos aspectos sociais, tecnológicos, culturais e filosóficos.

No entanto, essas novas técnicas de transmissão do conhecimento muitas vezes produzem nas escolas e, de forma mais específica nos professores, certa insegurança, dúvidas em relação à sua prática pedagógica, geralmente pelo fato de não conhecê-las a fundo, pois na maioria dos casos, o professor ainda não teve a oportunidade de estudá-las e por consequências não sabe aplicá-las em sua prática cotidiana. Assim, muitos utilizam as novas tendências apenas por estarem na "moda" e acabam no insucesso e ineficiência do processo didático-pedagógico.

Sabe-se que em toda ação, seja qual for seu campo de conhecimento, para que se efetue com êxito faz-se necessário o seu conhecimento de forma aprofundada, não podemos nos basear apenas numa visão empírica, o que acontece com um número significativo de professores e outros profissionais da educação, torna-se pertinente, a presença da ciência, de estudos que façam abordagens temáticas e que venham fundamentar a ação pedagógica.

A partir de então, busca-se desenvolver uma abordagem sobre uma temática muito aplicada no contexto escolar, mas que como pode-se perceber na maioria das salas de aula, acontece sem fundamentos sólidos que possam validar a prática docente e que pode induzir o indivíduo a transformar a sua própria vida e o espaço sociopolítico no qual está inserido. 
Utiliza-se como pressuposto para esta abordagem a pesquisa bibliográfica, analisando os fundamentos de autores como Ivani Fazenda (2005, 2007 e 2008) e Jurjo Santomé (1998), possibilitando maior aprofundamento desta temática.

Assim, aponta-se para a prática educativa interdisciplinar, à qual não se tem legado a importância devida, pois, como se sabe quando esta é realmente praticada na sua plenitude causa grande impacto sócio-educacional, revestindo o indivíduo de atitude a qual permite-o exercer influência em sua própria vivência.

Diante desta realidade, discutiremos no capítulo 2 sobre a prática educativa interdisciplinar destacando seu conceito e características. No capítulo 3, destaca-se as contribuições deste paradigma ao contexto educacional. No capítulo 4, enfatiza-se a construção do planejamento na consolidação de uma prática educativa interdisciplinar.

\section{INTERDISCIPLINARIDADE: CONCEITO E CARACTERÍSTICAS}

O processo de industrialização através da divisão do trabalho e da forte influência do capitalismo contribuiu de forma significativa para a fragmentação ocorrida nas instituições de ensino (SANTOMÉ, 1998). Toda essa influência teve como consequência uma prática educativa disciplinar e fragmentada, onde cada área de estudo apresentava conteúdos pré-estabelecidos, além de uma forte valorização de um conhecimento estático, puramente intelectual, sem elo algum com a realidade enfrentada pelo educando.

A prática educativa, até então, estava fundamentada em um estudo restrito a conteúdos metodológicos, e a preocupação da escola e do professor era com o desenvolvimento intelectual. Podemos identificar este momento na educação brasileira a partir do momento em que nos reportamos ao período pelo qual passou a educação, conhecido como Educação Tecnicista. Neste modelo paradigmático, o educando era preparado apenas com o fim de desempenhar uma função específica no campo do trabalho, assim, ele estudava apenas o necessário para desenvolver determinada função dentro da empresa, sem nenhuma autonomia. 
Segundo Santomé (1998, p.14):

Os conteúdos culturais que formavam o currículo escolar com excessiva frequência eram descontextualizados, distantes do mundo experiencial de alunos e alunas. As disciplinas escolares eram trabalhadas de forma isolada e, assim, não se propiciava a construção e a compreensão de nexos que permitissem sua estruturação com base na realidade.

Como a preocupação maior estava naquilo que seria produzido, o currículo adotado pelas instituições de ensino deveria transmitir um conhecimento restrito, pouco importava o que o aluno vivenciava no seu dia-a-dia, a sua opinião acerca da inflação, do alto custo de vida ou do preço da cesta básica, não importava, o que se buscava eram os lucros que aquele estudante-operário traria para determinadas empresas.

Com isso, não haveria a necessidade de um currículo que se voltasse ou se preocupasse em desenvolver aquele educando para que este viesse a ser um agente de sua própria realidade e assim, o processo didático-pedagógico acontecia de maneira vertical (professor/aluno), visto que o segundo elemento deveria receber um conhecimento pronto, acabado.

Porém, este quadro começa a mudar a partir das inquietações de pesquisadores e professores que se dispuseram a um estudo aprofundado da importância de um ensino globalizado, que facilitasse sua compreensão de tal modo que o levaria a refletir sobre sua própria realidade enquanto transformador do seu contexto sociocultural, partindo de uma visão crítica, pois, como afirma Behrens (2003, p.60) "a produção do conhecimento com autonomia, com criatividade, com criticidade e espírito investigativo provoca a interpretação do conhecimento e não apenas a sua aceitação". Com isso, é preciso levar em conta que o conhecimento tanto no campo cultural quanto no científico, deve ser observado vislumbrando sua prática interdisciplinar além de sua aplicabilidade na sociedade.

No Brasil, os estudos sobre a interdisciplinaridade têm início na década de 1970, a partir das inquietações e pesquisas nesta área de Ilton Japiassú, que desenvolvia 
seus estudos interdisciplinares a partir de uma visão epistemológica e Ivani Fazenda adotando mais um caráter de cunho pedagógico.

A partir desta visão de um ensino globalizador, ou seja, de um ensino onde o aluno é orientado a desenvolver suas capacidades e habilidades não somente dentro das disciplinas, mas contextualizando com aquilo que ele presencia no seu cotidiano, é que acontece a prática interdisciplinar. Severino (in FAZENDA, 2008) diz que essa interdisciplinaridade deve se impor tanto dentro da esfera pedagógico-educacional quanto na própria formação do indivíduo enquanto profissional e agente social.

Dessa forma, o termo interdisciplinaridade deve estar presente no cotidiano escolar não apenas numa visão teórica, porém na própria práxis pedagógica.

É interessante notar que no dia-a-dia da sala de aula, muitos educadores julgam-se interdisciplinares simplesmente pelo fato de desenvolver na sua prática uma fusão das disciplinas escolares de maneira superficial, porém, é notório que este processo constitui-se em algo que requer muito mais aprofundamento, pois propõe mudanças e estas devem acontecer de modo significativo na vida do educando.

Assim, para tratarmos do processo de ensino-aprendizagem dentro deste paradigma educacional, busquemos conhecê-lo, a princípio, a partir de sua estrutura epistemológica, fator evidenciado por Assumpção (in FAZENDA, 2005).

a) inter-: constitui um prefixo latino que significa posição, ação intermediária, reciprocidade, interação;

b) o vocábulo disciplina relaciona-se ao regime de ordem seja ele por imposição ou por consentimento;

c) e o sufixo -dade ou ainda, -idade, usado para substantivar alguns adjetivos apresenta o sentido de ação, qualidade ou modo de ser. 
A partir de então, entende-se que a "interdisciplinaridade é uma atitude, isto é, uma externalização de uma visão de mundo, que no caso é holística" (FERREIRA, 2005, p.22), ou seja, parte do indivíduo para o todo através da interação do conhecimento.

O termo Interdisciplinaridade surge assim, ligado à finalidade de se corrigir possíveis erros resultantes da intervenção do processo disciplinar, pois o que se pretendia na construção de um indivíduo era que este fosse não apenas intelectual, um "detentor" do conhecimento, mas também que fosse um ser sentimental, envolvido com o outro no sentido de trocar experiências, de mudar sua realidade.

De acordo com Ferreira (in FAZENDA, 2005, p.34):

O que caracteriza uma prática interdisciplinar é o sentimento intencional que ela carrega. Não há interdisciplinaridade se não há intenção consciente, clara e objetiva por parte daqueles que a praticam. Não havendo intenção de um projeto, podemos dialogar, inter-relacionar e integrar sem, no entanto, estarmos trabalhando interdisciplinarmente.

Percebe-se que uma atitude interdisciplinar requer de cada educador uma prática fundamentada principalmente naquilo que ele deseja ensinar e no que o aluno deseja aprender, neste caso se verifica a intencionalidade da ação pedagógica e a veracidade da construção de um saber interdisciplinarizado.

É importante salientar que este processo é ativo e exige desempenho, pois envolve as diversas áreas do saber, constitui fundamentalmente uma filosofia que interage nas decisões políticas com flexibilidade, ao mesmo tempo em que define problemas, interroga, questiona, determina conhecimentos, especifica estudos e pesquisas, reúne conhecimentos atuais construindo e mantendo comunicação através de técnicas integradoras que viabilizam uma melhor interatividade do indivíduo não só com ele próprio, mas com o mundo a partir de um propósito.

Para Fazenda (2005, p.18) "o que caracteriza a atitude interdisciplinar, é a ousadia da busca, da pesquisa: é a transformação da insegurança num exercício do pensar, num 
construir". Isso demonstra que o processo interdisciplinar apresentará algum entrave para acontecer, ou seja, na realização do projeto interdisciplinar as atividades muitas vezes surgem de um único indivíduo e então, lança-se como desafios ao grupo, existem ainda barreiras como a falta de materiais, pouca disponibilidade dos próprios profissionais e até mesmo da instituição.

Diante desses fatos, a ação pedagógica a partir deste paradigma transpõe estas barreiras e como consequência surge o desejo de criar, de inovar, de transformar a realidade dentro do conjunto através da troca de experiências, do diálogo.

Destaca-se a seguir a prática educativa interdisciplinar no ambiente escolar, enfatizando seus principais aspectos.

\section{A PRÁTICA EDUCATIVA INTERDISCIPLINAR NO CONTEXTO ESCOLAR}

Para delinearmos a prática educativa interdisciplinar cabe antes ressaltá-la dentro da visão da própria prática de ensino, evidenciando a questão de que se trata do resultado de um processo de busca do conhecimento sendo, portanto, sua concretização.

Assim, Severino (in FAZENDA, 2008, p.33) ressalta que "a educação como uma prática deve ser equacionada não em relação ao ser do homem, mas às modalidades de sua prática". Ele ainda complementa este pensamento afirmando que:

A questão básica [...] é a da relação do conhecimento como a prática humana. Daí a importância do vínculo do conhecimento pedagógico com a prática educacional. Seu caráter interdisciplinar tem a ver com essa condição. (Idem)

Percebemos fortemente este vínculo no desenvolvimento da ação educativa quando bem elaborada e transposta à realidade sócio-educacional. Na verdade, a grande dificuldade ao tentar se estabelecer uma visão interdisciplinar na prática educativa 
está basicamente voltada à questão do diálogo, pois compreende-se que esta não se consolida de forma isolada e fragmentada.

Com isso, diante desta problemática a escola ainda com vista a esta fragmentação busca inventar projetos interdisciplinares, quando em sua ação pedagógica falta atitude em relação à definição de um currículo que realmente se desenvolva dentro do que se chama de pedagogia interdisciplinar, visto que esta exige atitude dos parceiros da ação.

Concorda-se com Fazenda (2007, p. 64) quando esta destaca que:

A atitude interdisciplinar não está na junção de conteúdos, nem na junção de métodos; muito menos na junção de disciplinas, nem na criação de novos conteúdos produtos dessas funções; a atitude interdisciplinar está contida nas pessoas que pensam o projeto educativo.

Para tanto, torna-se pertinente à questão interdisciplinar que esta se firme no contexto educacional a partir da visão filosófica, fator preponderante nesta ação, que permitirá maior abrangência desta temática levando-se em consideração relações sistêmicas e assistêmicas no campo sócio-histórico do aluno, impedindo-se que esta se transforme em um objeto de alienação. (FAZENDA, 2007, p.37)

A interdisciplinaridade ao ser interpretada por muitos autores decorre o risco de perder as suas características maior que a concepção única do conhecimento, com isso na construção e formação do conhecimento é relevante a junção ou integração das muitas disciplinas ou ciências, pois garante sua execução de forma mais eficiente. Pode ser vista como um encontro de saberes que enriquece o processo de ensino e aprendizagem.

Na prática educativa a uma diversidade de conceitos, dinâmicas e tendências que nem sempre enfocam a interdisciplinaridade como deveriam, no entanto, há um jeito 
que liga essa prática norteando os saberes adquiridos por ambos que fazem que fazem parte do ensino aprendizagem.

A multiplicidade desses saberes leva ao questionamento de uma prática educativa mais sólida, na consolidação de ideias e propósitos bem estruturados, pois nada está acabado, há que fazer, sempre haverá perguntas, mas sempre haveria respostas.

Freire (1996, p.41), diz que:

Uma das tarefas mais importantes da prática educativo-crítica é propiciar as condições em que os educandos em suas relações uns com os outros e todos com o professor ou a professora ensaiam a experiência profunda de assumir-se. Assumir-se como ser social e histórico como ser pensante, comunicante, transformador, criador realizador de sonhos, capaz de ter raiva porque é capaz de amar.

Assim, a prática educativa em suma precisa atuar de tal modo na realidade do educando que este assuma uma posição crítica no contexto no qual está inserido. No entanto, percebe-se a prática interdisciplinar a partir do momento em que há uma contextualização dessa prática, ou seja, quando o educando envolve-se no processo ensino-aprendizagem e ao mesmo tempo impõe-se como idealizador e transformador de sua própria realidade.

Portanto, a interdisciplinaridade, torna-se indispensável dentro do contexto educacional, visto que ela além de trabalhar a pluralidade dos elementos que o envolve, permite também uma visão diferenciada ao homem, que na sua singularidade expõe a evolução das suas ideias.

Fazenda $(2005$, p.17) ao ressaltar a cerca da realização de projetos interdisciplinares diz que:

No processo interdisciplinar não se ensina, nem se aprende: vive-se, exerce-se. A responsabilidade individual é a marca do projeto 
interdisciplinar, mas essa responsabilidade está imbuída do envolvimento - envolvimento esse que diz respeito ao projeto em si, as pessoas e as instituições a ele pertencente.

Desta forma, percebe-se a responsabilidade do conjunto na construção do conhecimento, quando se trata de educação todo contexto social precisa está envolvido desde a própria sociedade até a escola, e ao se perceber esse trabalho mútuo, detecta - se na prática educativa a ação interdisciplinar visto que existe a uma execução de uma proposta educacional transformadora.

No que tange ao processo interdisciplinar dentro da escola podemos ainda ressaltar um elemento primordial no desenvolvimento da ação educativa, diz respeito ao planejamento, a sua construção implica a priori revisar a questão da construção de um currículo globalizado e interdisciplinar.

Contudo, percebe-se o caráter emancipatório da ação educativa interdisciplinar no contexto escolar. Assim, no próximo capítulo estaremos destacando a construção deste elemento importante que é o planejamento dentro de uma visão educativa interdisciplinar.

\section{A CONSTRUÇÃO DO PLANEJAMENTO NA CONSOLIDAÇÃO DE UMA PRÁTICA EDUCATIVA INTERDISCIPLINAR}

A construção de um currículo globalizado e interdisciplinar exige que o processo educativo aconteça a partir da valorização de aspectos abrangendo sua formação no campo social, cognitivo, psicológico, etc. Este modelo de currículo segundo Santomé (1998, p.27) terá que:

[...] converter-se em uma categoria guarda-chuva capaz de uma ampla variedade de práticas educacionais desenvolvidas nas salas de aula, e é um exemplo significativo do interesse em analisar a forma mais apropriada de contribuir para melhorar os processos de ensino e aprendizagem. 
Neste sentido, percebe-se que o currículo escolar relaciona-se ao conceito de interdisciplinaridade a partir do momento que este permite uma abertura para conhecimentos culturais não estagnados, um maior acesso ao conhecimento que é construído focalizando os pilares da educação, ou seja, o aluno estará estimulado a desenvolver-se no sentido de aprender a ser, aprender a conhecer, aprender a fazer e a aprender a aprender, pois compreendemos que estes elementos estão interligados no processo de aquisição do conhecimento.

Por sua vez, o conhecimento para ser um objeto de mediação precisa estar muito bem elaborado, neste sentido o planejamento escolar deve ser significativo e eficaz, ao ponto que neste processo de construção e reconstrução do conhecimento sejam desenvolvidas as habilidades, as competências, os conceitos, as atitudes e os valores, hábitos que identificam o verdadeiro indivíduo que está preparado para viver em sociedade.

O planejamento, segundo Vasconcelos (2006), deve apresentar-se como um modelo que possibilita uma mudança generalizada, que estimule o aluno a ter atitude diante da realidade a qual vivência e ao mesmo tempo tomar um posicionamento crítico que o possibilite transformar sua própria comunidade escolar. A partir deste ponto de vista, reflete-se acerca do planejamento enquanto um elemento de construção na aplicação da prática educativa interdisciplinar.

O seu papel será como o de uma águia no processo de renovação da própria vida, a qual sobe no topo mais alto de uma montanha e lá trava uma intensa luta para sobreviver, até trocar o bico, trocar as pernas e com uma nova vida voa em busca de grandes aventuras.

$\mathrm{Na}$ produção do planejamento, ocorre semelhante fato, pois quando o educador se percebe com uma prática esgotada é através da busca por conhecimento e por sua vez, da elaboração deste conhecimento que ele se utiliza do ato de planejar sua ação pedagógica. Neste ato, ele utiliza novos elementos para melhor colocar em ação os conhecimentos conquistados com tanto esforço, quando esteve ali participando de 
encontros, seminários e outras capacitações, tudo em busca de novos conhecimentos que viabilizam sua prática com eficiência, e, este é então, o momento de um voo de uma ave renovada, o momento da execução e da prática.

O planejamento surge como meio de organizar o conhecimento a ser transmitido, apresenta uma intenção, a qual se pode assim dizer, mantém uma relação com três fatores que na atualidade tem direcionado o processo de produção do conhecimento e na formação sociocultural do educando, quando este interage de forma a modificar sua própria realidade. Estes elementos que constitui $O$ ato de planejar são: os conceituais, os procedimentais e os atitudinais (ZABALA, 1998).

Os elementos conceituais dizem respeito ao conteúdo pronto, aquele que irá viabilizar os conhecimentos técnicos e científicos, refere-se a fatos e produz um caráter reprodutivo pelo qual o principal resultado é a repetição; os procedimentais estão voltados à capacidade do aluno saber fazer, agir de maneira eficiente diante daquilo que Ihe foi proposto; e os atitudinais, que a princípio fundamenta-se a partir de três elementos básicos, os quais são a cognição, a afetividade e a conduta estes abrangem simultaneamente os valores e as atitudes diante da sociedade. $\mathrm{O}$ último elemento tem ganhado maior ênfase dentro da comunidade escolar, pois se acredita que através dele obtém-se melhor relacionamento dentro do contexto escolar, e até da própria sociedade (ZABALA, 1998).

Contudo, cabe destacar que estes objetivos de estudos promovem na prática educativa maior transformação da realidade do educando e valoriza a construção do conhecimento e suas intervenções de mudanças promovendo a prática interdisciplinar.

\section{CONSIDERAÇÕES FINAIS}

A Prática Educativa Interdisciplinar abordada neste trabalho quando adotada no ensino e aprendizagem de forma a promover uma atitude transformadora pode contribuir para o aperfeiçoamento do espaço escolar e do convívio do aluno em sua comunidade. 
Constatou-se que a interdisciplinaridade no contexto escolar, aponta para a atribuição de competências com intencionalidade através da expressão de atitudes sentimentalistas por meio de ações, e essas ações resultam numa busca constante do ser, do saber, levando-nos a aprender a aprender.

Há sempre a necessidade de se buscar novos caminhos para se compreender melhor a realidade, realidade essa que envolve e torna o indivíduo cada vez mais em um ser pensante, com a responsabilidade de atuar na sociedade promovendo mudanças.

É importante ressaltar que existe essa necessidade da escola trabalhar de forma a envolver a equipe pedagógica, o corpo docente e a própria comunidade de em um trabalho interdisciplinar. Pois como ficou claro, desenvolver trabalhos voltados para a integração de várias áreas do conhecimento exige de todos os envolvidos compromissos, mas não apenas com a prática, porém com a busca de teorias que realmente fundamentem a prática interdisciplinar.

Percebeu-se que os desafios são muitos na trajetória de uma educação integradora, com efeitos morais que estabelecem a organização, por isso a interdisciplinaridade, deve ser entendida como articuladora do conhecimento e ao mesmo tempo flexível, pois ela é indissociável do processo educativo, o qual viabiliza a formação do ser humano desde a educação infantil até a educação superior, com grande ênfase no fortalecimento de projetos que façam do processo educativo, algo dinâmico e emancipador.

Conclui-se dizendo que a prática educativa interdisciplinar quando desenvolvida de maneira eficiente no contexto educacional, tem como tendência expandir-se significativamente em âmbitos diversos da sociedade, contudo promovendo a partir da interação a transformação do meio.

\section{REFERÊNCIAS}

BEHRENS, Marilda Aparecida. O paradigma emergente e a prática pedagógica. 3ed. Curitiba: Champagnat, 2003. 
CAMPOS, Casemiro de Medeiros. Saberes docentes e autonomia dos professores. Petrópolis, RJ: Ed. Vozes, 2007.

FAZENDA, Ivani. (org.) Didática e Interdisciplinaridade. 13ed. Campinas, São Paulo: Papirus, 2008.

(org.). Práticas Interdisciplinares na escola. 11ed. Campinas, São

Paulo: Cortez, 2005.

. Interdisciplinaridade: um projeto em parceria. 6ed. Campinas, São

Paulo: Loyola, 2007.

FREIRE, Paulo. Pedagogia da autonomia: saberes necessários a prática educativa. 28ed. São Paulo: Paz e Terra, 1996.

SANTOMÉ, Jurjo Torres. Globalização e interdisciplinaridade: o currículo integrado. Porto Alegre: Editora Artes Médicas Sul Ltda, 1998.

VASCONCELOS, Celso dos Santos. Planejamento: Projeto de ensino aprendizagem e Projeto Político Pedagógico. 16ed. São Paulo: Libertad, 2006.

ZABALA, Antoni. A prática educativa. Porto Alegre: Artmed, 1998.

Enviado: Agosto, 2019.

Aprovado: Fevereiro, 2020. 